\title{
Analysing the Concept of Municipal Budgeting and Service Delivery Pattern in a South Africa's District Municipality
}

\author{
Emmanuel Imuezerua
}

Elizabeth Chinomona

\author{
Faculty of Management Sciences, Vaal University of Technology, P.Bag X021, Vanderbijilpark. 1900
}

Email: chakubvae@hotmail.com/emmaimuez@gmail.com

\section{Doi:10.5901/mjss.2015.v6n1p359}

\section{Abstract}

Budget allocation and expenditure patterns in South African municipalities have been a matter of concern as it affects its service delivery. The South African government has clear policies which state that municipalities and municipal officials should be sensitive to community views and problems. The recognition of municipality as a sphere of government enhances the status of municipalities which gives them the role of providing community services. To this end, there is a need for efficacy of financial management and accurate budgeting mechanisms to transform the municipalities into a better place. This accumulation of service delivery and the deteriorating infrastructure has placed a burden on municipal budgets. The inadequate financial management capacity for example, in the area of budgeting skills and its allocation, has given rise to the current ineffective service delivery in municipalities. The inadequacy in the area of budgeting skills and allocation as it affects service delivery motivated this research. The study also investigated how budgetary allocation and expenditure patterns can lead to optimal delivery of services for the benefit of the community it serves. Using SPSS 22.0 this study tested the validity and reliability of the measurement instruments used. Managerial implications of the findings are discussed and limitations and future research directions are indicated.

Keywords: Municipality, Budgeting, Service delivery, Financial accounting, Financial resources

\section{Introduction}

The history of local authority in South Africa during the 20th century was that of racial segregation (Fataar 2003; Soudien 2010). The pre 1994 government made cities in South Africa develop along unequal social and economic lines. It was the primary role of local government during this era, to create local separation and inequality. Accordingly, Pieterse (2002) noted that the crisis in local government was a key force which led to the national reform process that began in the 1980's against the distortion of human settlements, which contributed to the collapse of the apartheid local government. In an effort to redress the apartheid legacies, the government elected in April 1994 reformed previous legislations and policies to address issues pertaining to separation, inequality, poverty and to establish new transitional local authorities (Jansen 2003; Allais 2012). The municipal system in South Africa is thus largely understood in terms of service delivery. The Local Government White Paper of 1998 (section b, 2.1) reiterates the responsibilities of the local governments'- to include the provision of a basic level of service delivery with the following objectives:

- to enable municipalities extend affordable basic services to all South Africans;

- to support municipalities in improving the performance of service delivery systems; and

- to assist coordination between sectorial delivery programmes.

The Constitution of the Republic of South Africa, 1996, as amended has clear policies which state that municipalities and municipal officials should be sensitive to community views and problems. The recognition of municipality as a sphere of government in Chapter 7 of the Constitution of South Africa, 1996, as amended enhances the status of municipalities which gives them the role of providing community services. To this end, there is a need for effective financial management and accurate budgeting mechanisms to transform the municipalities into a better place.

The municipality has executive and legislative authority vested in its municipal council and the right to govern the affairs of its community, subject to national and provincial government legislation, as provided for in the South African Constitution. The municipal authority, by virtue of its developmental role, is expected to structure and manage the administration; budgeting and planning processes in a way that prioritises the basic needs of the community it serves (Haycock, 2005). Hence, optimum performance is vital in order to eradicate the accumulation in the delivery of social 
services (Erasmus, 2008). The effectiveness and efficiency of the municipality to deliver on a mandate is largely dependent on its ability to plan and allocate resources in a developmental and sustainable manner (Valeta\& Walton, 2008). Hence, this study aim to analyse the municipal budget and its effect on service delivered to the communities.

\section{Literature Review}

Prior to 1994, the financial arrangements for municipalities in South Africa were regulated by ordinances passed by the then four provinces namely: Gauteng, Free State, Cape Town and Kwazulu Natal. In 1996, the Local Government Transition Act was amended to include a new section, which dealt with property rates and user fees, loans, investments and budgets. These legislations were aimed at combating the maladministration in the handling of government finance and distribution of infrastructural facilities in the past. Amongst these legislation is the Municipal Finance and Management Act (MFMA) (Act 56 of 2003). It contains a complete synopsis of all the legislative requirements pertaining to municipal budgets including the legally assigned roles and responsibilities. The framework for municipal finance can be traced back to the White Paper on Local Government issued in 1998 which has the Constitution of South Africa at the centre which specifically requires that all local government must be developmentally oriented and that basic needs of the respective communities are met in budgeting and administration. Consequently, budget is prepared in the course of administering the day to day activity of the municipality.

\subsection{Municipality}

The Constitution of the Republic of South Africa, 1996, as amended, in section 155(3a), stipulates the criteria for the formation of a municipality, and is also stated in the Municipal Structures Act of 1998. In South Africa, there are presently two hundred and eighty - four (284) municipalities which are divided into; Metropolitan municipalities, Local municipalities, and District municipalities. In South Africa, municipality is a "tier of government" that lie one level down from provincial government forming the lowest level of democratically elected government in the country. The municipality is in charge with the responsibility of delivering services to the community, and in order to attain this, finance and proper budgeting is needed. Municipal services are of crucial importance to the growth, development and stability of a community. Accordingly, sections 152 and 153 of the Constitution of South Africa, 1996, as amended, set out the objects of local government and the developmental duties of municipalities.

It is required that municipalities provide services in a sustainable style and that municipal administrations provide services objectively, fairly, equitably and without bias. The Municipal Structures Act (117 of 1998) provides that municipality has the functions and powers assigned to it in terms of sections 156 and 229 of the Constitution. Such powers must be divided between a district municipality and local municipalities within the area of a district municipality. The Act further requires a district municipality to achieve the integrated, sustainable equitable social and economic development of its area as a whole.

\subsection{Budgeting}

CIMA (2006) defines budget as a quantitative expression of a plan for a defined period of time which may include planned revenues, resource quantities, cost and expenses, assets, liabilities and cash flows. A budget is also defined by Guide to Municipal Finance (2009) as a document which sets out the municipality plan for revenue and expenditure for an annual or multi - year period. Challenged to meet significant demands for services with limited available resources, government in South Africa committed itself to modernise the management of the public sector and to allocate the necessary resources to make it more people friendly and sensitive to the communities it serves. Budgetary and financial reforms were initiated soon after the1994 elections. A major step forward began in 1997 with the introduction of a new intergovernmental system, which required all three spheres to develop and adopt their own budgets (Treasury Guidelines 2002).

This was accompanied by a system of significant transfers to provinces and municipalities. In the 1998 Budget, Government set out 3-year rolling spending plans for national and provincial departments under the Medium Term Expenditure Framework-the MTEF. Medium - term budgeting is the basis of the budget reform initiatives. It reinforces the link between Government's policy choices, its budget and the delivery of services, which serves to strengthen political decision-making and accountability. Policy choices and trade-offs are made explicit, spending decisions are kept affordable in the medium-term, and there is better management of public finances over time. Medium-term budgeting broadens the scope of financial management to include a strong focus on service delivery. In, 1999 National Expenditure 
Survey set out the policies and aims of national departments; budgeting and spending trends over a seven- year period, including medium-term expenditure estimates; and indicators of services delivered by national departments. Such service delivery information shows how public money is being spent, enabling political decision - makers to make informed decisions on budget allocations in line with policy priorities and service delivery targets. Different processes and types of budget are appropriate depending on the type of institution. In other words, to make a performance system successful, both the composition and the performance management systems of the municipality need to be of high quality (De - Waal \& Gerritsen, 2006). This is achieved when goals, objectives and targets are set to decide the appropriate schedules for the inputs necessary for task performance (Kent - John, 2008). Budgeting is an important mechanism in a municipality which gives effect to its revenue and expenditure. The final elements in this phase of reforms were to deepen the budget process and better align policy, planning and budgeting.

\subsection{Service delivery}

Service delivery can be regarded as the availability of essential and quality infrastructure and amenities to citizens of a country or a community (OECD, 2008). In an effort to improving service delivery efficiency and quality in communities, the pre 1994 government gave way for a new approach to local government to be developmental and aims to overcome the poor planning of the past approach (Bundy 2005; Sehoole 2008; Oloyede 2009). The Integrated Development Plan (IDP) was introduced and this is an approach to planning that involves its citizens in finding the best solutions to achieve long term development. IDP is a super plan for an area that gives an overall framework for development. If the budget is aligned to the IDP by means of the Service Delivery and Budget Implementation Plan (SDBIP), it will result in effective service delivery.

The SDBIP provides the vital link between the mayor, council (executive) and the administration, and facilitates the process for holding management accountable for its performance. The SDBIP is a management, implementation and monitoring tool that will assist the mayor, councillors, municipal manager, senior managers and community. A properly formulated SDBIP will ensure that appropriate information is circulated internally and externally for purposes of monitoring the execution of the budget, performance of senior management and achievement of the strategic objectives set by council. It enables the municipal manager to monitor the performance of senior managers, the mayor to monitor the performance of the municipal manager, and for the community to monitor the performance of the municipality. The SDBIP should therefore determine (and be consistent with) the performance agreements between the mayor and the municipal manager and the municipal manager and senior managers determined at the start of every financial year and approved by the mayor. It must also be consistent with out sourced service delivery agreements such as municipal entities, publicprivate partnerships, service contracts and the like (MFMA, 2003).

\subsection{Financial accounting and financial resources}

Libby, Libby and Short (2001) defined financial accounting as the classification and recording of monetary transactions, the presentation and interpretation of the results of those transactions in order to assess performance over a period. The accounting profession adopted a set of standards and procedures called generally accepted accounting principles (GAAP) and this has gained acceptance over the time because of its universal application. On the other hand, the business dictionary defines financial resources as the money available to a business for spending in the form of cash, liquid securities and credit lines. Financial resources are important in order to be able to operate efficiently to promote success. Financial management has become one area in the municipality which poses a challenge hence effective management through budgeting ensures that there are funds available to implement the municipality's policies and the delivery of service that affect the lives of the people (Mkhize\&Ajam, 2006).

\section{Research Methodology}

Cronbach's Alpha, factor loadings and item-to-total correlations (a statistical test used in order to generate internal consistency of the questionnaire) to test the reliability and validity of the data collected is explained. The purpose of this study is to gain an understanding into the budget allocation and expenditure patterns of Sedibeng District Municipality. The target population of forty (40) used for this research were heads of department in the Budget and Integrated Development Plan, managers, assistant managers and municipal officials involved with budget preparation and integrated development plan within the municipality. 


\subsection{Sample Procedure}

There are two different types of sampling procedures - probability and non-probability sampling. A probability sampling method ensures that there is a possibility for each person in a sample population to be selected whereas a non probability method targets specific individuals. For this study the convenience sample was used. This is a non-probability sample not because the samples are easy to recruit, but because the researcher uses whatever individual was available rather than selecting from the entire population (Wilson 2010). Convenience sampling also reports large number of demographic factors to see the likeness of representativeness. Another researcher who has used convenience sampling in research is Gozdziak \& Bump (2008:31) in the study for data and research on human trafficking. It was applied in this study because individuals could be reached easily.

\subsection{Sample Size}

Goddard \& Melville (as quoted by Okubena, 2007:128) asserts that the correct sample size in a study is dependent on the nature of the population and the significance of the study. In practice, the sample size used is determined, based on the expense of data collection and the need to have sufficient statistical control. Sample size affects accuracy of representation and a larger sample means less chance of error. For this research the sample of forty (40) officials from the Sedibeng District Municipality were involved while thirty four (34) represent the sample size population, which represent $85 \%$ who responded. This sample size was generated with the help of sample size calculator called RAOSOFT. Raosoft is an innovative survey software programmes for information gathering and analysis. It is the statistical software used in the calculation of sample size. The choice in sample size of forty (40) is consistent with Tustin, Ligthelm, Martins and Van Wyk (2005:360) who states that for any research, a sample size larger than thirty (30) and smaller than five hundred (500) are appropriate. In the calculation of the sample size, three factors were considered: margin of error, the confidence interval and the percentage of the sample that will chose a given answer to a survey question. In order to address different constructs a Likert, scale was used. The Likert scale establishes the extent of agreement or disagreement with statements (e.g strongly agree, agree, neutral, disagree and strongly disagree). This scale was used because the study was intended to be scientific and must therefore comply with the hope that the final outcome will gain a wider acceptability.

\subsection{Respondent Profile}

Table 1, outlines the response rates of the gender of respondents within the surveyed municipality. It shows $65 \%$ were male while $35 \%$ are female which reflects the involvement of large percentage of male than female in the administration of the municipal budget and service delivery. The rate of age distribution of respondents within the municipality indicates that those within the ages of 31- 40 years were $53 \%$, $41-50$ years were $29 \%, 51-60$ years were $6 \%$ while those $<30$ years were $12 \%$. This shows that the work force within the municipality are young and full of energy which can be translated into effective and efficient delivery of duties within the municipality. This is consistent with Meijen (2007:56) who stated that employees' age has an effect on the commitment and how well the municipality performs and delivers its services. Sedibeng District Municipality comprises three local municipalities: Emfuleni local municipality, Lesedi local municipality and Mid Vaal local municipality. The survey confirms that $9 \%$ of the respondents were head of departments while $91 \%$ represent others which include senior officials of the Budget department and that of the Integrated Development Plan department.

The response indicates that $76 \%$ of the respondents have worked for less than fifteen years; $15 \%$ have worked for between 16 - 30 years while $6 \%$ have worked for between 31 - 40 years while $3 \%$ of the respondents did not respond to the question, which was regarded as missing value. From the illustration in table 1 , above, $82 \%$ of the respondents have worked in the present position for less than 10 years, 12\% have worked for between 11 - 20 years while 3\% have worked for between $21-30$ years and another $3 \%$ of the respondents have worked for more than 30 years. This is a strong indication that officials in the Budget department and Integrated Development Plan department are not experienced considering the possibility of a number of the official not having experience in the public sector. Results indicates $32 \%$ of the respondents are university degree holders, $47 \%$ are holders of a diploma, and $15 \%$ are holders of matric while $6 \%$ are classified as others which included non-completion of matric or workshop seminar attendance. These however show that the work force in the municipality is literate although over half of the respondents possessed less than a degree. Muller (2009:1) notes that for efficient, effective and sustainable provision of services in the municipality, managers and staff of the municipality require competence in the form of academic qualification. When municipal officials are less 
educated, the officials will be less likely to find legitimate ways of making the municipality well structured. The implication therefore is that when the municipality is not well structured, it can lead to ineffective service delivery which eventually leads to protest by the communities as have been witnessed in various Provinces within South Africa.

Table 1: Diagrammatic Presentation of all Sample Demographic Characteristics

\begin{tabular}{|c|c|}
\hline Gender & Percentage \\
\hline Male & $65 \%$ \\
\hline Female & $35 \%$ \\
\hline Total & $100 \%$ \\
\hline Age & Percentage \\
\hline Under 30 years & $12 \%$ \\
\hline $31-40$ years & $53 \%$ \\
\hline $41-50$ years & $29 \%$ \\
\hline $41-60$ years & $6 \%$ \\
\hline Total & $100 \%$ \\
\hline Post/Office of Respondents & Percentage \\
\hline Head of Department & $9 \%$ \\
\hline Others & $91 \%$ \\
\hline Total & $100 \%$ \\
\hline Participants working experience & Percentage \\
\hline$\leqq 10$ years & $82 \%$ \\
\hline $11-20$ years & $12 \%$ \\
\hline $21-30$ years & $3 \%$ \\
\hline More than 30 years & $3 \%$ \\
\hline Total & $100 \%$ \\
\hline Academic Qualifications & Percentage \\
\hline Diploma & $47 \%$ \\
\hline Degree & $32 \%$ \\
\hline Matric & $15 \%$ \\
\hline Others & $6 \%$ \\
\hline Total & $100 \%$ \\
\hline
\end{tabular}

\subsection{Data Analysis}

This study used SPSS 22.0 technique (Ringle, Wende\& Will 2005). Since the sample size small (34) checking reliability and validity of measurement instruments was found to be more useful in this study. Below is Table 2 presenting evidence on the reliability and validity. As can be seen (Table 2), all items have loadings greater than 0.6 (i.e. ranging from 0.510 to 0.690. As such, this confirms that all the measurement items converged well on their respective constructs and therefore are statistically significant.

Table 2: Reliability and Validity

\begin{tabular}{|l|c|c|c|}
\hline & $\begin{array}{c}\text { Factor } \\
\text { Loadings }\end{array}$ & $\begin{array}{c}\text { Item-total } \\
\text { correlations }\end{array}$ & $\begin{array}{c}\text { Cronbach's alpha } \\
\text { coefficients }\end{array}$ \\
\hline $\begin{array}{l}\text { Q4-1 A budget is an expression, in monetary terms of the financial } \\
\text { decisions of the municipal council, in that it indicates the expected income } \\
\text { and expenditure for a specific financial year. }\end{array}$ & 0.690 & 0.650 & 0.661 \\
\hline $\begin{array}{l}\text { Q4-3 The municipality approves an annual budget before the start of a } \\
\text { new financial year. }\end{array}$ & 0.688 & 0.558 & \\
\hline $\begin{array}{l}\text { Q4-5 The annual budget of the municipality is divided into capital and } \\
\text { operating components using established norms as prescribed in section } \\
\text { 17(2) of the MFMA. }\end{array}$ & 0.630 & 0.692 & \\
\hline
\end{tabular}




\begin{tabular}{|l|c|c|c|}
\hline Q4-10 The budget reflects line items within each class of expenditure. & 0.610 & 0.500 & \\
\hline $\begin{array}{l}\text { Q4-11 The municipal council budget is approved on or before 30th June of } \\
\text { each year as prescribed by section 24(2)(a) of MFMA. }\end{array}$ & 0.610 & 0.500 & \\
\hline $\begin{array}{l}\text { Q4-15 Budget detail information is available and easily accessible on and } \\
\text { off line for consultation by citizens as prescribed in section 17(3) of MFMA. }\end{array}$ & 0.620 & 0.618 & \\
\hline $\begin{array}{l}\text { Q4-16 Short falls in budgeted revenue and overspending of the } \\
\text { municipality budget is reported in writing to the municipal council by the } \\
\text { accounting officer of the municipality. }\end{array}$ & 0.652 & 0.600 & \\
\hline $\begin{array}{l}\text { Q5-4 The budgeted expenditure passes through competitive tender's } \\
\text { panel before awarded on merit }\end{array}$ & 0.550 & 0.667 & 0.602 \\
\hline $\begin{array}{l}\text { Q5-7 The percentage of operating expenses expended on salaries and } \\
\text { allowances exceed 35\% of the total annual budget }\end{array}$ & 0.510 & 0.623 & \\
\hline $\begin{array}{l}\text { Q5-12 The performance indicators are sufficiently well designed such that } \\
\text { one can assess whether there has been progress toward meeting policy } \\
\text { goals. }\end{array}$ & 0.509 & 0.620 & \\
\hline Q5-17 Municipality annual budget identifies earmarked revenues & 0.543 & 0.652 & \\
\hline
\end{tabular}

\subsection{Reliability}

The degree in which data collection reflects transparency and congruency with other research in similar topic is known as reliability. Similarly, if the result of a study can be reproduced under the same methodology, the instrument is acclaimed to be reliable. Reliability is concerned with consistency of measures and the level of instruments reliability is dependent on its ability to produce the same result when used repeatedly (Leedy \& Ormrod, 2006:9). The Cronbach's alpha was used to measure the reliability in this study. The Cronbach alpha is a test for a surveys internal consistency which is also called the scale reliability test. The Cronbach alpha measures how well each individual items in a scale correlates with the remaining items. The Coefficient alpha value ranges from 0 to 1 . A value of 0.60 and above suggests a satisfactory level of reliability while lower values are sometimes used in the literature (Anderson \& Gerbing 1988). Reliability for this study was informed through the following:

- pre-testing the instrument used in the study through a pilot study;

- discussions were held with the supervisor and the statistician because of experience in similar studies;

- having the questionnaire reviewed by the supervisor and the statistician;

- open ended questions were kept to the minimum; formulating response scales that are likely to increase the validity of responses; and

- performing a thorough review of the literature in the field of study.

According to Gerber - Nel (as quoted by Okubena, 2010:139), the response and non response errors can also pose a serious threat to the reliability of data and this must be minimised by the researcher. Response errors are the estimated inaccuracies that can be introduced by the researcher, the interviewer or the respondents. For this study however, response errors were minimised by carefully constructing and pre testing the questionnaires. On the other hand, the non-response error occurs because respondent who responds to the survey might not have attributed a similar response to those who do not. Nonetheless, the non-response errors for this study were reduced to the minimum by using self-administered questionnaires, which involved a direct meeting with respondents and by removing sensitive questions from the questionnaire.

The results show that Q4 and Q5 questions are reliable because the Cronbach alphas are above 0.6 which is the recommended threshold by Anderson and Gerbing (1988). Q4 the Cronbach alpha is 0.661 and Q5 the Cronbach alpha is 0. 602. This shows that Q4 and Q5 questions are on the same range considering the reliability of the constructs.

\subsection{Validity}

Validity is the extent to which a test measures what it claims to measure, and is vital for a test to be valid in order for the result to be accurately applied and interpreted. Validity assesses whether the research instruments being used truly measures that which it was intended to measure. A valid instrument must cover the extent to which it provides adequate coverage of the variables being used (Yin, 2003:81). Hence for this study, the following validity was considered:

- using a statistician to evaluate the research instrument for clarity;

- pre-testing the research instrument in a pilot study; 
- sampling was done using probability methods ensuring external population validity;

- using self-administered questionnaires which generally have a high response rate;

- using a sample size with margin of error of not more than 5\% and a confidence level of 95\%; and

- reviewing the literature for theoretical constructs and empirical conclusions

In this study the validity of the instruments was measured using the factor loadings and item-to-total correlations. On Q4 questions, 10 questionnaires were deleted because the factor loadings were below 0.5 (Anderson \& Gerbing 1988). On Q5, 13 questionnaires were deleted because they did not meet the threshold which is above 0.5. On Q4 questions, Q4-1"A budget is an expression, in monetary terms of the financial decisions of the municipal council, in that it indicates the expected income and expenditure for a specific financial year", has the highest factor loading of 0.690 and highest item to total of 0.650 . Q4-10,"The budget reflects line items within each class of expenditure" and Q4-11,"The municipal council budget is approved on or before $30^{\text {th }}$ June of each year as prescribed by section", have the lowest factor loadings of 0.610 and lowest item to total correlations of 0.500 . On Q5 questions, Q5-4, "The budgeted expenditure passes through competitive tender's panel before awarded on merit", has the highest factor loading of 0.550 and highest item-to total of 0.667. Q5-12, "The performance indicators are sufficiently well designed such that one can assess whether there has been progress toward meeting policy goals," has the lowest factor loading of 0.509 and lowest item to total of 0.620 .

\section{Recommendations}

Recently, a number of service delivery protests throughout the country (Olifantshoek in the Northern Cape and Modderdam in Cape Town) have confirmed that challenges exist in municipalities. For municipalities to fulfil its developmental mandate given by the Constitution of the Republic of South Africa, Act 108 of 1996, as amended, it is important for these challenges to be identified and analysed. These challenges should therefore be contextualised so as to develop responses and proper planning. The following recommendations will help the Sedibeng District Municipality to deliver service more effectively to the communities:

\subsection{Need for Human Development}

Municipality as a tier of government is dynamic in nature because it is closest to the people in the community. Its dynamic nature and the functions it performs make it ideal for an educated and experienced work force. The researcher noted that human development is the key to developing the characteristics required for proper budgetary application. Presently, a greater percentage of the work force (82\%) have less than ten years work experience while only $32 \%$ of the work force are degree holders. The study noted the need for Sedibeng District Municipality to organise budget planning and budget implementation seminars for officials in charge of finance and those in the IDP department. The researcher therefore recommends that budget planning and implementation workshops and seminars should be organised for these officials frequently. This will enhance a better understanding of the execution and implementation of the approved budget that has been aligned to the IDP for effective service delivery to the communities.

\subsection{Improved Revenue Collection}

The South African constitution framework created a multi sphere system of government. The intergovernmental fiscal system is based on "revenue sharing" with national and provincial government receiving the bulk. The researchers noted that the revenue collection pattern of the municipality is not maximised. It is the recommendation of the researcher, therefore, that the budget of the municipality be maximised holistically through provision of a prepaid mode of payment (Pre- paid meter services) to some of the services (water and electricity) provided. The benefit of managing this service delivery (electricity and water) through the introduction of a prepaid meter will advance the revenue of the municipality. Anyone found to be involved in any form of corruption should be prosecuted in the law court. In addition, the researcher recommends that the municipality develop a stable tax base from rates, service charges and property tax since over reliance on inter government transfers can endanger municipal delivery of service.

\subsection{Improving Local Participation}

Improved local participation by the municipality will reduce protests by the community. The current practice where the councillors alone represent the ward should be reviewed. The recommendation of the researcher is that the municipality 
secure greater participation by community. Apart from being a Constitutional and legislative requirement, it is also an important principle of effective governance. To achieve greater public participation, the following are recommended: (a) improvement of communication between communities. It is through communication that the plans of the municipality can be clearly articulated and understood by the communities. A proper delivery strategy is adapted through interaction with the community members; (b) integrated public education and programmes; (c) provision of adequate operational requirements to enhance public participation.

\subsection{Compliance to Approved Budget}

Strict compliance to the approved annual budget of the municipality should be adhered to and if there is any expenses not approved, that must be incurred and a full disclosure of such should be made.

\subsection{Borrowed Funds}

In order to assist the municipality in addressing a major service delivery issue, funds can be borrowed to finance capital improvement. However, it was noted that presently, the municipality's lack of experience in developing the capital improvement as a way to meet the criteria of the financier is the bane of the municipality. The researcher recommends an organised, well-conceived demand for finance to substantiate interest by lenders in the affairs of the municipality. Borrowed funds should also be used for whatever project it was meant for as deviation is tantamount to operating without an approved budget.

\subsection{Public Private Partnership with Established Service Provider}

The municipality should be involved more in partnership with a service provider, which will improve service delivery since this service providers are professionals in this area and all the municipality need do is to monitor the service provider for appropriate implementation of policy. In carrying out this study however, a number of limitations were encountered and these are discussed in the following section.

\section{Limitations to the Study}

The findings of this study should be viewed with certain limitations in mind. These, however, present opportunities for future research studies.

- Firstly, even though literature is available on budget and expenditure, there is little reference linked to municipality and service delivery.

- Secondly, the respondents were reluctant to give information about the municipality as municipalities in South Africa remains a challenge. Respondents delayed in filling the questionnaire for fear of implication. The researcher had to continually convince the respondents that it was purely for academic purposes.

- Thirdly, the scope of the study was limited by the sample size which included only officials of Sedibeng District Municipality. This revealed only a small portion of municipal findings which may have been different if a broader range of staff from other municipalities had been selected.

- Finally, respondents choose to tick the options given in the questionnaire (5 Likert scale) and refused to give statements in the space provided which shows a limitation in the survey method.

\section{Areas for Further Research}

In order to understand why communities are involved in protests all around South Africa due to ineffective service delivery by municipalities, future study should widen its scope beyond Sedibeng District Municipality. The research could be done across South Africa using two municipalities from the different categories of municipality (Metropolitan, District and Local municipality). In summary, the area for further research is for the researcher to provide insights that are relevant and useful to improve effective and efficient delivery of service by municipalities across South Africa.

In future researchers might opt for collecting data on large samples such that other techniques of data analysis can be used like Structural Equation Modeling and Smart PLS. This might yield very reliable and valid results since the bigger the sample the more reliable and valid the study (Hair, Babin, Anderson \&Tatham 2010). 


\section{Conclusion}

This study evaluated the budget allocation and expenditure pattern of Sedibeng District Municipality on Service Delivery. Since the 1994 democratic election, South Africa have been plagued by service delivery protest that has caused havoc in both urban and rural societies, often resulting in police involvement, serious injuries and great damage to communities. Proper budgeting by municipalities across South Africa will ensure that the hitherto limited funds are used for effectiveness in the allocation of service delivery. However, the budgetary allocation of the municipal fund is embedded in the budget control function. It is through the proper budgetary allocation that fruitful benefit may be attained in terms of service delivery to communities.

\section{References}

Allais, S. (2010). The Implementation and Impact of Qualifications Frameworks: Report of a Study in 16 Countries. International Labour Office,Geneva.

Bekink, B. (2006). Principles of South Africa Local Government Law. Durban: LexisNexis.

Bundy, C. (2005). Global patterns, local options? Some implications for South Africa of international changes in higher edication. Perspectives inEducation, 23(2), 85-98.

CIMA. (2006). Budgeting Topic. Gateway Series No. 27. Great Britain: CIMA.

De - Waal, A.A. \& Gerritsen, M. G. (2006). Performance Management Analysis: a case study at Dutch Municipality. Journal on productivity and performance management 55(1): 26.

Erasmus, L. T. (2008). Assessing Financial Performance in South Africa Public Service. Journal of Public Administration. 43(3): 401.

Fataar, A. (2003). Higher Education policy discourse in South Africa: a struggle for alignment with macro development policy. SAJHE/ SATHO,17(2), 31-39.

Guide to Municipal Finance. (2009). The Human Settlements Financing Tools and Best Practices Series. Kenya: United Nations.

Hair, J. F., Anderson, R.E., Tatham, R.L. \& Black, W.C. (2006). Multivariate Data Analysis. $6^{\text {th }}$ ed. London: Prentice-Hall.

Haycock, K. (2005). Development of Communication Strategy for the non-payment of Services: a case of Mogale city. Journal of Public Administration: conference proceedings, $49-50$.

Jansen, J.D. (2003). On the state of South African Universities. SAJHE/SATHO. 17(3), 9-12.

Kent - John, C. (2008). How to Develop an Effective Budget System. Journal on new directions for higher education, 107:17.

Libby, R., Libby, P. A. \& Short, D.G. (2001). Financial Accounting. USA: McGraw Hill.

Mkhize, N. \& Ajam, T. (2006). The New Budgeting Approach in South Africa: a critical assessment. Journal of Public Management. 41(4): $760-761$.

OECD. (2008). Journal of Development. Vol 9, No. 3.

Oloyede, O. (2009). Critical reflection on the report of the Ministerial Committee on Transformation, Social cohesion and the elimination ofdiscrimination in Public higher education. Perspectives in Education, 27(40), 426-434.

Pieterse, E. (2002).From Divided to Integrated City? Critical overview of the emerging metropolitan governance system in Cape Town. Urban Forum Journal, Vol. 13, Issue 1, pg. 28.

Republic of South Africa. (1996). Constitution of the Republic of South Africa 1996 as amended. Pretoria: Government Printers.

Republic of South Africa. (1998). Local Government Municipal Structures Act 117 of 1998. Pretoria: Department of Local Government.

Republic of South Africa. (2002). Treasury Guidelines: Budgeting, planning and measuring service delivery. Pretoria: Government Printers.

Republic of South Africa. (2003). Municipal Finance Management Act (No 56 of 2003). Pretoria: Department of Local Government.

Sehoole, C. (2008). Internationalisation of higher education in South Africa: A historical review. Perspectives in Education, 24(4), 1-23.

Soudien, C. (2010). Grasping the nettle? South African higher education and its transformative imperatives. South African Journal of HigherEducation, 24 (6), 881-896.

Valeta, L. \& Walton, G. K. (2008). Integrated Development Planning and Budgeting at Local Government. Journal of Public Administration. 43(3.1):374.

Wilson, J. (2010). Essentials of Business Research. A guide to doing your research project. Great Britain: Sage Publications. 